\title{
Silencing of pancreatic adenocarcinoma upregulated factor by RNA interference inhibits the malignant phenotypes of human colorectal cancer cells
}

\author{
PENG-FEI LIU ${ }^{1 *}$, YUN-YUN WU $^{1 *}$, YOU HU ${ }^{1}$, LEI WANG ${ }^{1}$, SONG-BING HE ${ }^{1,2}$, YI-BEI ZHU ${ }^{3}$ and XIN-GUO ZHU ${ }^{1}$ \\ ${ }^{1}$ Department of General Surgery, The First Affiliated Hospital of Soochow University, Suzhou, Jiangsu 215006; \\ ${ }^{2}$ Institute of Health Sciences and Shanghai Institutes of Immunology, Shanghai Institutes for Biological Sciences, Chinese \\ Academy of Sciences and Shanghai Jiao Tong University School of Medicine, Shanghai 200025; ${ }^{3}$ Department of \\ Immunology, The First Affiliated Hospital of Soochow University, Suzhou, Jiangsu 215006, P.R. China
}

Received February 28, 2013; Accepted April 26, 2013

DOI: $10.3892 /$ or.2013.2478

\begin{abstract}
Aberrant expression of pancreatic adenocarcinoma upregulated factor (PAUF), a novel secretory protein, has been reported in several types of cancer. However, in colorectal cancer (CRC), whether PAUF also plays its oncogenic role through the Wnt/ $\beta$-catenin pathway and its effect in regulating malignant phenotypes of CRC is unknown. In this study, we detected PAUF and $\beta$-catenin expression levels by immunohistochemical analysis and real-time PCR in CRC tissues, adjacent non-tumor tissues (NATs) and 5 CRC cell lines. The results demonstrated that the expression of PAUF and $\beta$-catenin in tumor tissues was higher than in NATs. Moreover, the expression of PAUF was correlated with the expression of $\beta$-catenin in both tumor tissues and NATs. The HCT116 cell line, which has the highest PAUF expression of the 5 cell lines, was transfected with small interfering RNA (siRNA) targeting on PAUF, which significantly downregulated the expression of PAUF in cancer cells. Successful transfection was confirmed by using RT-PCR and western blot analysis. Further studies demonstrated that PAUF-siRNA inhibited the proliferation of CRC cells, promoted their apoptosis and induced G0/G1 cell cycle arrest. At the same time, PAUF-siRNA inhibited the invasion, adhesion and migration of the tumor cells. In conclusion, this study suggested that PAUF was expressed in CRC at a high frequency. Interference of PAUF may be an effective strategy for regulating malignant phenotypes of CRC through the Wnt/ $\beta$-catenin pathway.
\end{abstract}

Correspondence to: Professor Xin-Guo Zhu or Dr Song-Bing He, Department of General Surgery, The First Affiliated Hospital of Soochow University, 188 Shizi Street, Suzhou, Jiangsu 215006, P.R. China

E-mail: captain_hesongbing@hotmail.com

E-mail: captain_hsb@163.com

*Contributed equally

Key words: colorectal cancer, pancreatic adenocarcinoma upregulated factor, Wnt/ $\beta$-catenin, RNA interference

\section{Introduction}

Colorectal cancer (CRC) continues to be a leading malignancy in gastrointestinal tumors. It has been reported that CRC is the fourth most common cancer and the second leading cause of cancer-related mortality in the United States (1-3). Although significant progress has been made in the treatment of CRC, it is still difficult to treat advanced CRC, which has a poor prognosis and a $40 \%$ overall mortality rate $(4,5)$. Thus, understanding the molecular mechanisms of CRC progression may help to develop more efficient therapy strategies for the disease.

The Wnt/ $\beta$-catenin pathway involved in the early development process of various types of cancer is also involved in the development of CRC $(6,7)$. The key step in activating the Wnt pathway is the stabilization of $\beta$-catenin and its translocation into the nucleus, which may serve as a potential target for CRC therapy (8). Therefore, clarifying the mechanism of $\beta$-catenin regulation may aid in the diagnosis and treatment of CRC (9-11). The latest research shows that pancreatic adenocarcinoma upregulated factor (PAUF), a novel secretory protein, may be one of the regulatory genes of $\beta$-catenin (12).

PAUF, as a newly discovered oncogene, has been reported to play its oncogenic role by upregulating the expression of $\beta$-catenin and increasing its transcriptional activity in pancreatic cancer (13). Researchers also found that PAUF is highly expressed in pancreatic cancer tissues as well as in colon, ovary and stomach cancer tissues $(12,13)$. However, in CRC, whether PAUF also play its oncogenic role through the increase of $\beta$-catenin expression and upregulation of its transcriptional activity remains unknown.

In the present study, we detected the expression of PAUF and $\beta$-catenin in CRC and investigated whether PAUF affected the biological behavior of CRC through the adjustment of the Wnt/ $\beta$-catenin pathway by RNA interference.

\section{Materials and methods}

Reagents. Rabbit anti-human PAUF antibody, rabbit antihuman $\beta$-catenin antibody, rat anti-human $\beta$-actin antibody and goat anti-rabbit IgG secondary antibody were purchased 
from Santa Cruz Biotechnology, Inc. (Santa Cruz, CA, USA). Lipofectamine ${ }^{\mathrm{TM}} 2000$ was provided by Invitrogen Life Technologies (Carlsbad, CA, USA). RT-PCR kits were purchased from Fermentas (USA). Small interfering RNA (siRNA)-PAUF were designed and synthesized by GenePharma Co., Ltd. (Shanghai, China). Annexin V apoptosis kit (Keygentec, China) and Matrigel (BD Biosciences, San Jose, CA, USA) were used in the present study.

Cell lines and tissue samples. The human CRC cell lines (SW480, LoVo, SW1116, SW620 and HCT116) were purchased from the Chinese Academy of Sciences (Shanghai, China). The cell lines were seeded in 6-well plates at a density of $1.5 \times 10^{5} /$ well and maintained in RPMI-1640 (Invitrogen Life Technologies) supplemented with $10 \%$ fetal bovine serum (FBS; Sijiqing Biological Engineering Materials Co., Hangzhou, China). All cells were cultured at $37^{\circ} \mathrm{C}$ in a humidified atmosphere containing $5 \% \mathrm{CO}_{2}$. Surgical specimens of CRC tissue and their corresponding adjacent non-tumor tissues (NATs) (at least $2 \mathrm{~cm}$ distance from the tumor site) were obtained from 48 patients at the Department of General Surgery, the First Affiliated Hospital of Soochow University, from 2008-2010. All patients had a clear histological diagnosis of CRC, based on the clinicopathological criteria described by the UICC. Informed consent was obtained from all the patients and research protocols were approved by the Independent Ethics Committee (IEC) of our hospital.

Immunohistochemical analysis. For immunohistochemical analysis, samples were fixed in $10 \%$ neutral formaldehyde, embedded in paraffin and sliced. Briefly, the paraffin-embedded tissues were serially cut into $4 \mu \mathrm{m}$ sections, dewaxed and rehydrated. Sections were then blocked with peroxide and non-immune animal serum and incubated sequentially with rat anti-human PAUF and $\beta$-catenin (1:1,000), and biotin-labeled goat anti-rabbit $\operatorname{IgG}(1: 1,000)$. Finally, the sections were stained with DBA, counterstained with hematoxylin, dehydrated, cleared in xylene, and fixed. Histological assessment was performed as previously described (2). Immunostaining was independently examined by two clinical pathologists. Five high-power fields (x400 magnification) were randomly counted for each section. The brown staining on the cytoplasm was read as positive reactivity for PAUF and $\beta$-catenin. The presence of brown colored granules on the cytoplasm was considered a positive signal, and was divided by color intensity into not colored, light yellow, brown, tan, and was recorded as $0,1,2,3$, respectively. We also selected five high-power fields from each slice and scored them. A positive cell rate of $<25 \%$ was a score of 1 , a positive cell rate of $25-50 \%$ was a score of 2 , a positive cell rate of $51-75 \%$ was a score of 3 , and a positive cell rate of $>75 \%$ was a score of 4 . The final score was determined by multiplying positive cell rate and score values: 0 was equal to negative (-), 1-4 was equal to weakly positive $(+), 5-8$ was equal to moderate positive (++), 9-12 was equal to strongly positive (+++).

Transfection of cells with PAUF-siRNA. PAUF-siRNA sequences were designed and synthesized by GenePharma Co., Ltd. (Table I), which included 3 sets of 25-nucleotide stealth RNAi targeting PAUF, and a fluorescently labeled
Table I. Synthesized oligonucleotide sequences for siRNA.

\begin{tabular}{ll}
\hline Primer & \multicolumn{1}{c}{ Sequence } \\
\hline PAUF-siRNA1 & \\
Sense & 5'-UCCCUGGGUAUUCCCACCUAAGGCU-3' \\
Antisense & 5'-AGCCUUAGGUGGGAAUACCCAGGAA-3' \\
PAUF-siRNA & \\
Sense & 5'-AAAUAGAAAUAGCGGUCCUUGCUGG-3' \\
Antisense & 5'-CCAGCAAGGACCGCUAUUUCUAUUU-3' \\
PAUF-siRNA & \\
Sense & 5'-GAGUAUGUGAGAUUAACUGGUGGC-3' \\
Antisense & 5'-GCCACCAGUUAAUCUCACAUACUCA-3' \\
FAM-negative- & \\
control & \\
Sense & 5'-UUCUCCGAACGUGUCACGUTT-3' \\
Antisense & 5'-ACGUGACACGUUCGGAGAATT-3' \\
Negative-control & \\
Sense & 5'-UUCUCCGAACGUGUCACGUTT-3' \\
Antisense & 5'-ACGUACACGUUCGGAGAATT-3' \\
\hline
\end{tabular}

siRNA, small interfering RNA.

siRNA oligos segment which was used to detect the transfection efficacy by flow cytometric analysis (FACS). HCT116 cells $\left(1.5 \times 10^{5}\right)$ were divided into 6 groups: (i) PAUF-siRNA1, (ii) PAUF-siRNA2, (iii) PAUF-siRNA3, (iv) scrambled siRNA and (v) non-siRNA control. Cells were transfected with PAUFsiRNA or negative control siRNA using Lipofectamine 2000 (Invitrogen Life Technologies), according to the manufacturer's protocol. Cells were exposed to siRNA in Dulbecco's modified Eagle's medium (DMEM) for $6 \mathrm{~h}$, after which the medium was replaced with DMEM containing 10\% FBS and the cells were incubated for $48 \mathrm{~h}$. Our preliminary study confirmed that the maximal transfection efficacy is obtained when the ratio of Lipofectamine 2000 to siRNA is $4 \mu \mathrm{l}: 4 \mu \mathrm{l}$. At $48 \mathrm{~h}$ post-transfecion, cells were harvested and subjected to total RNA extraction and adhesion, migration and invasion assay. Secreted protein was prepared from culture medium at $48 \mathrm{~h}$ post-transfection.

RT-PCR and real-time PCR gene expression analysis. The mRNA expression of PAUF and $\beta$-catenin in HCT116 cells following PAUF-siRNA transfection were quantified by RT-PCR. Total RNA was isolated from cells using TRIzol Reagent (Invitrogen Life Technologies) and quantified. cDNA was synthesized from $5 \mu \mathrm{g}$ of RNA using AMV reverse transcriptase (Fermentas) according to the manufacturer's instructions. PAUF and $\beta$-catenin were amplified from the cDNA by RT-PCR. The PCR conditions consisted of $5 \mathrm{~min}$ at $95^{\circ} \mathrm{C} 1$ cycle, $30 \mathrm{sec}$ at $95^{\circ} \mathrm{C}, 30 \mathrm{sec}$ at $55^{\circ} \mathrm{C}, 30 \mathrm{sec}$ at $72^{\circ} \mathrm{C}$ and $7 \mathrm{~min}$ at $72^{\circ} \mathrm{C} 35$ cycles. The primer sequences were: PAUF forward, 5'-CACCTGGGCAGGGAAGATGTA-3' and reverse, 5'-GCTCAGTGGTCGGCTCCTCT-3'; $\beta$-catenin forward, 5'-TGCCAAGTGGGTGGTATAGAG-3' and reverse, 5'-TGG GATGGTGGGTGTAAGAG-3'; $\beta$-actin forward, 5'-AACTC CATCATGAAGGGTTGTGA-3' and reverse, 5'-ACTCCTG CTTGCTGATCCAC-3'. 
The mRNA expression of PAUF and $\beta$-catenin in 12 CRC samples was quantified by real-time PCR. A total of $200 \mathrm{mg}$ of tumor tissues or NATs was homogenized in liquid nitrogen. Total RNA was extracted and reverse transcribed into cDNA, which was then used for amplification of PAUF and $\beta$-catenin. The real-time PCR conditions consisted of 1 cycle at $95^{\circ} \mathrm{C}$ for $10 \mathrm{~min}$ followed by 35 cycles at $95^{\circ} \mathrm{C}$ for $30 \mathrm{sec}$, at $55^{\circ} \mathrm{C}$ for $30 \mathrm{sec}$ and at $72^{\circ} \mathrm{C}$ for $30 \mathrm{sec}$. GAPDH was employed as an internal standard. The primer sequences were: PAUF forward, 5'-CCTGGAGGAGGCAAGTATTTCA-3' and reverse, 5'-GACCTACAGACACCCGCAGC-3'; $\beta$-catenin forward, 5'-TGCCAAGTGGGTGGTATAGAG-3' and reverse, 5'-TGGGATGGTGGGTGTAAGAG-3'; GAPDH forward, 5'-AGGGGCCATCCACAGTCTTC-3' and reverse, 5'-AGAA GGCTGGGGCTCATTTG-3'. The $2^{-\Delta \Delta C T}$ method was applied to analyze the relative changes in gene expression.

Western blot analysis. After $72 \mathrm{~h}$ of transfection, protein was extracted from HCT116 cells as previously described by Kim et al (12), and then subjected to SDS-PAGE. Protein concentrations were transferred onto PVDF membranes and the membranes were then blocked and incubated with rabbit anti-human PAUF $(1: 1,000)$ or $\beta$-catenin antibody $(1: 1,000)$ at $4^{\circ} \mathrm{C}$ overnight. After 3 washes with TBST solution for $10 \mathrm{~min}$, the membranes underwent hybridization with a goat anti-rabbit IgG secondary antibody $(1: 1,000)$ at $37^{\circ} \mathrm{C}$ for $1 \mathrm{~h}$. After further washing, PAUF and $\beta$-catenin levels were visualized using an ECL chemiluminescence kit.

MTT assay. HCT116 cells were digested, re-suspended and seeded in a 96-well culture plate $6 \mathrm{~h}$ after transfection. After 24,48 and $72 \mathrm{~h}$ of incubation, cells were stained with $20 \mu \mathrm{l}$ MTT solution $(5 \mathrm{mg} / \mathrm{ml})$ at $37^{\circ} \mathrm{C}$ for $4 \mathrm{~h}$ and subsequently made soluble in $150 \mu \mathrm{l}$ DMSO. The reaction product was quantified by measuring the absorbance (A) of $490 \mathrm{~nm}$ at room temperature.

Flow cytometric analysis. Transfection efficiency was estimated with the use of fluorescein phosphoramidite (FAM)antisense oligodeoxynucleotides by fluorescence-activated cell sorter (FACS). Cells were transfected with the mixture of Lipofectamine 2000 and FAM-NC-siRNA according to a pre-set mixing ratio. After successful transfection, cells were harvested and washed with phosphate buffered saline (PBS) twice. The maximal transfection efficacy could then be tested by FACS.

Cells were trypsinized and centrifuged at $1,500 \mathrm{rpm} / \mathrm{min}$ for $5 \mathrm{~min}$ at $48 \mathrm{~h}$ after transfection. Cells were harvested and washed with PBS twice. Reagents for apoptosis detection were added and then cells were incubated in the dark for $30 \mathrm{~min}$ and subjected to FACS. Cells were collected, washed with PBS, fixed with $75 \%$ ethanol at $20^{\circ} \mathrm{C}$ overnight, and centrifuged at $1,500 \mathrm{rpm} / \mathrm{min}$ for $5 \mathrm{~min}$. Then, ethanol was removed and cells were washed with PBS twice. Propidium iodide (PI) and $500 \mu \mathrm{l}$ of RNase were added and the cells were incubated in the dark at $4^{\circ} \mathrm{C}$ for $60 \mathrm{~min}$. Lastly, cells were subjected to cell cycle analysis by FACS.

Cell invasion assay. Invasion capability in vitro was measured in Transwell chambers (CoStar Group Inc., Washington, DC,
USA) according to the manufacturer's protocol. Briefly, the upper chambers of the Transwell inserts were coated with $100 \mathrm{ml}$ diluted Matrigel solution at $37^{\circ} \mathrm{C}$ for $4 \mathrm{~h}$, and then pretreated with serum-free RPMI- 1640 medium at $37^{\circ} \mathrm{C}$ for $1 \mathrm{~h}$ before seeding the cells at a density of $1 \times 10^{5} /$ well in $100 \mu \mathrm{l}$ medium with $1 \%$ FBS. The lower chambers were filled with $500 \mathrm{ml}$ RPMI-1640 with 10\% FBS and HCT116 contained medium as a chemoattractant. The Transwells were then incubated at $37^{\circ} \mathrm{C}$ with $5 \% \mathrm{CO}_{2}$ for $48 \mathrm{~h}$ to allow cells to migrate. At the end of the incubation, the cells on the upper side of the insert filter were completely removed by wiping with a cotton swab, and the cells that had invaded through the Matrigelcoated filter were fixed in ethanol and stained with crystal violet. For quantification, the cells were counted under a microscope on 5 random fields at x100. Dye bound to the cells was solubilized with $0.1 \%$ SDS, and absorbance at $560 \mathrm{~nm}$ was measured. The A560 value represents the number of cells that had invaded through the Matrigel-coated filter.

Cell adhesion assay. Subsequently, 96-well plates were coated with Matrigel $(2.5 \mathrm{mg} / \mathrm{ml}) 100 \mu 1,4^{\circ} \mathrm{C}$ overnight. Cells exposed to siRNA for $48 \mathrm{~h}$ were seeded at a density of $1 \times 10^{4} / 100 \mu \mathrm{l}$ and then incubated for $80 \mathrm{~min}$. Five duplicate wells were set up for each group. At the end of the experiment, cells were washed twice with PBS to remove non-adherent cells. Cells that adhered to the substrate were stained with crystal violet. Dye bound to adhered cells was solubilized with $0.1 \%$ SDS, and absorbance at $560 \mathrm{~nm}$ was measured.

Cell migration assay. Cell migration assay was performed by the wound-healing method. Cells $\left(1 \times 10^{5}\right)$ exposed to adenovirus or siRNA for $48 \mathrm{~h}$ were plated in 6-well plates and grown to confluence. The monolayer was wounded by scratching with a sterile pipette tip lengthwise along the chamber. After wounding, cells were washed twice with PBS and cultured at $37^{\circ} \mathrm{C}$ for $24 \mathrm{~h}$. Images were captured immediately after cell wounding $(0 \mathrm{~h})$ and $24 \mathrm{~h}$ after cell wounding. Wound width $(\mu \mathrm{m})$ was measured using OpenLab software. Wound healing rate $=(0 \mathrm{~h}$ scratch width $-24 \mathrm{~h}$ scratch width $) / 0 \mathrm{~h}$ scratch width $\mathrm{x} 100 \%$.

Statistical analysis. Statistical analysis was performed with SPSS17.0 software (SPSS Inc, Chicago, IL, USA). Data are expressed as the means \pm standard deviation (SD). A Student's t-test was used for comparisons between groups, and F-test was applied for correlation analyses. A value of $\mathrm{P}<0.05$ was considered to indicate a statistically significant difference.

\section{Results}

Increased expression of PAUF and $\beta$-catenin in CRC tissues and NATs. To investigate the expression of PAUF and $\beta$-catenin in CRC, we detected the expression of PAUF and $\beta$-catenin in fresh CRC tissues and NATs from the same patient. Real-time PCR analysis showed that mRNA expression levels of PAUF and $\beta$-catenin in tumor tissues were significantly higher than in NATs $(\mathrm{P}<0.05)$ (Fig. $1 \mathrm{~B}$ and $\mathrm{C})$. In addition, the expression of PAUF was correlated with the expression of $\beta$-catenin in both tumor tissues $(r=0.658$, $\mathrm{P}<0.05)$ and NATs $(\mathrm{r}=0.732, \mathrm{P}<0.05)$. 
A

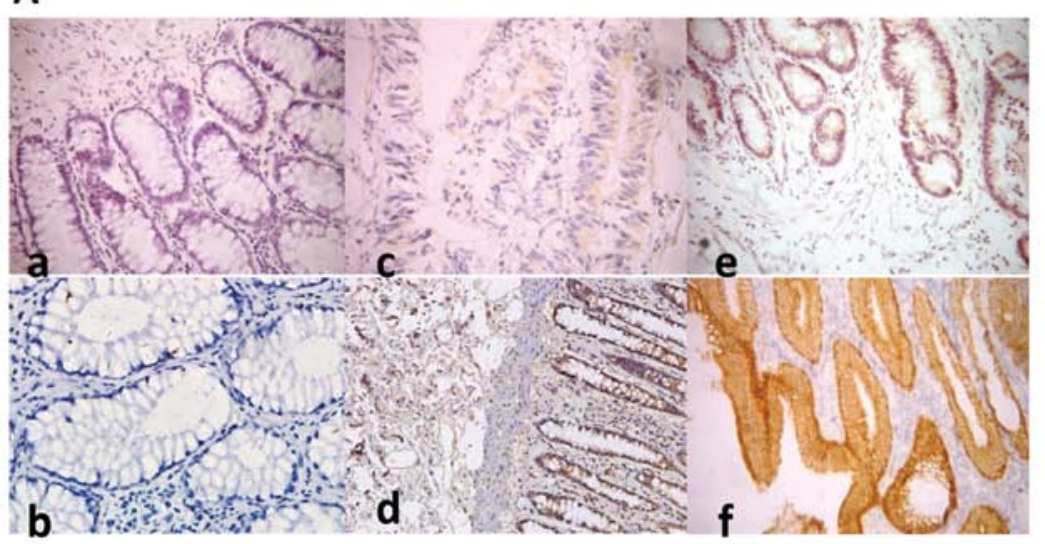

B

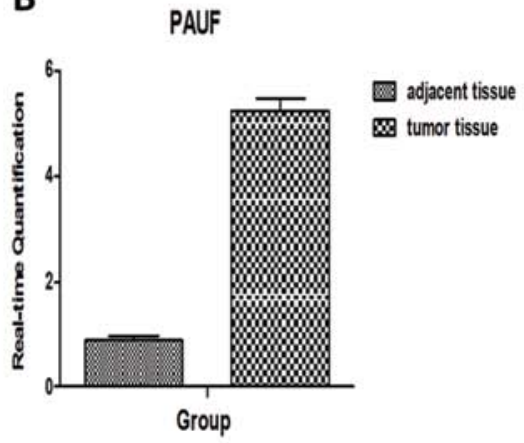

C

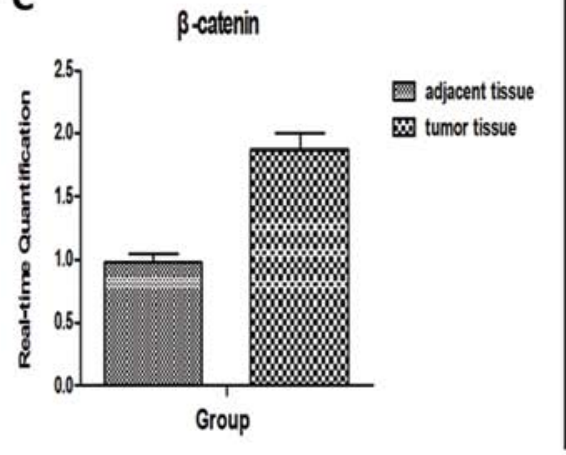

D
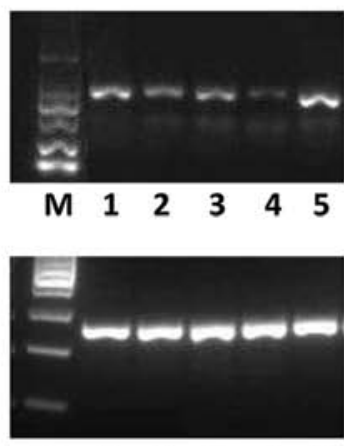

$\begin{array}{llllll}M & 6 & 7 & 8 & 9 & 10\end{array}$

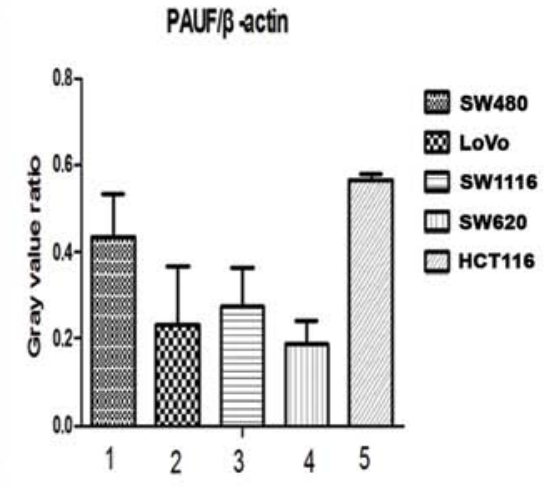

Figure 1. The expression of pancreatic adenocarcinoma upregulated factor (PAUF) and $\beta$-catenin in colorectal cancer (CRC), adjacent non-tumor tissues (NATs) and CRC cells. (A) Immunohistochemical analysis of CRC and NATs for expression of PAUF and $\beta$-catenin protein. The expression of PAUF (a,c,e) and $\beta$-catenin (b,d,f) was stained brown and was present in cancer tissue and NATs. Representative sites with negative (a, $\mathrm{x} 400)$, moderate positive (c, $\mathrm{x} 400)$, strongly positive (e, x400) expression of PAUF and corresponding weakly positive (b, $\mathrm{x} 400)$, moderate positive (d, $\mathrm{x} 400)$, strongly positive (f, $\mathrm{x} 400)$ expression of $\beta$-catenin. (B and C) Relative mRNA expression of PAUF and $\beta$-catenin in CRC and NATs detected by real-time PCR. (D) Relative expression of PAUF mRNA in CRC cells detected by RT-PCR: Lanes 1,2,3,4,5 represent PAUF mRNA expression of SW480, LoVo, SW1116, SW620 and HCT116, respectively. Lanes 6-10 represent corresponding internal reference. M, marker. Results are given as average value of the gray in 3 target genes and internal controls from 3 independent experiments.

Consistent with these results, immunohistochemical analysis showed strong cytoplasmic overexpression of PAUF and $\beta$-catenin in cancer cells was clearly observed; however, NATs did not react with the antibody (Fig. 1A). Of the $48 \mathrm{CRCs}$, the positive rate of PAUF and $\beta$-catenin was $62.5 \%$ (30/48) and $91.7 \%$ (44/48). However, in NATs, the positive rate was $16.7 \%$ (8/48) and $81.3 \%$ (39/48), respectively. The difference between them was statistically significant $(\mathrm{P}<0.05)$. As anticipated, the expression of PAUF was also correlated with the expression of $\beta$-catenin in the tumor tissues $(r=0.355, \mathrm{P}<0.05)$ and NATs $(\mathrm{r}=0.416, \mathrm{P}<0.05)$.

Transfection of CRC cells with PAUF-siRNA inhibits $m R N A$ and protein expression of PAUF and $\beta$-catenin. RT-PCR results showed that PAUF was expressed in all 5 CRC cell lines (SW480, LoVo, SW1116, SW620 and HCT116) at a high frequency, and the HCT116 cell line showed the highest elevation of PAUF mRNA among the 5 cell lines (Fig. 1D). In order to achieve a significant interference effect, we used the HCT116 cell line for the follow-up experiment.

A fluorescently labeled siRNA oligos segment was used to detect the transfection efficacy by FACS. Our study confirmed that the maximal transfection efficacy could be obtained when the ratio of Lipofectamine 2000 to siRNA was $4 \mu \mathrm{l}: 4 \mu \mathrm{l}$. Increase of the reagents did not improve transfection efficiency (Fig. 2). Three siRNA oligos segments targeting PAUF were designed to knock down PAUF (Table I).

To test the efficacy of PAUF siRNA in downregulating the expression of PAUF, we evaluated the PAUF expression in transfected cells at the transcript and protein level. The results demonstrated that mRNA and protein expression of PAUF were reduced by the 3 siRNA oligos segments to varying degrees, compared with the scrambled siRNA group and the non-siRNA group $(\mathrm{P}<0.05)$ and the no. 2 siRNA oligos segment (PAUF-siRNA2 group) was the most efficient. However, there was no significant difference between the scrambled siRNA group and the non-siRNA group (Fig. 3A and C). In addition, PAUF-siRNA transfection downregulated the expression of PAUF in HCT116 cells, which was also associated with a decrease in the expression of $\beta$-catenin, and the PAUF-siRNA2 group was also the most efficient (Fig. 3B and D). In order to achieve a significant interference effect, PAUF-siRNA2 was selected for subsequent experiments. 


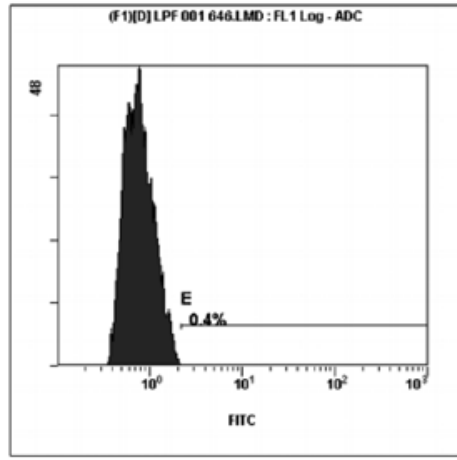

The blank group

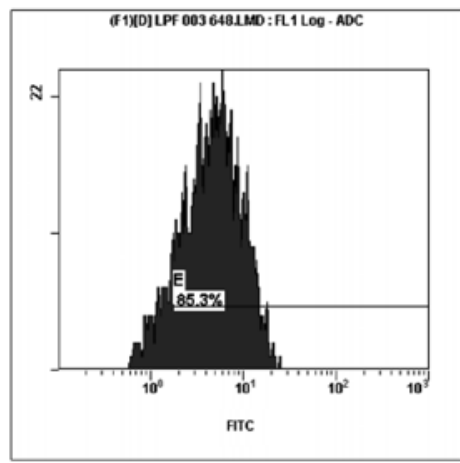

$1 \mu \mathrm{l}: 3 \mu \mathrm{l}$

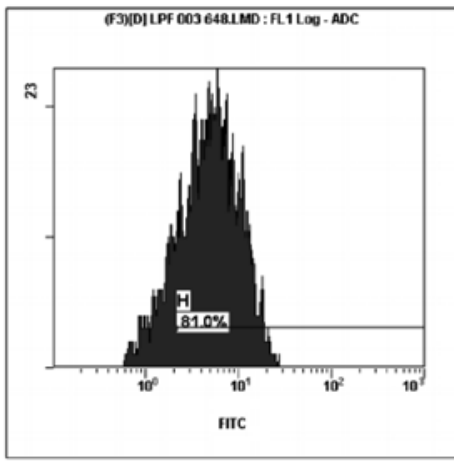

$1 \mu \mathrm{l}: 2 \mu \mathrm{l}$

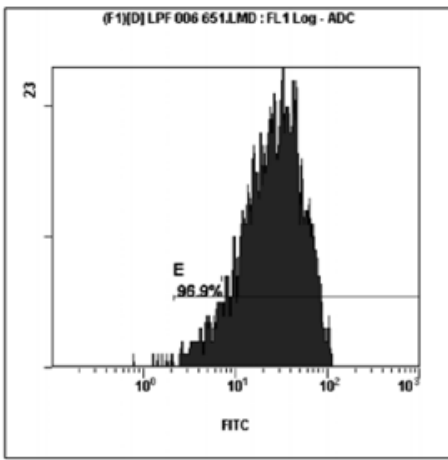

$4 \mu \mathrm{l}: 4 \mu \mathrm{l}$

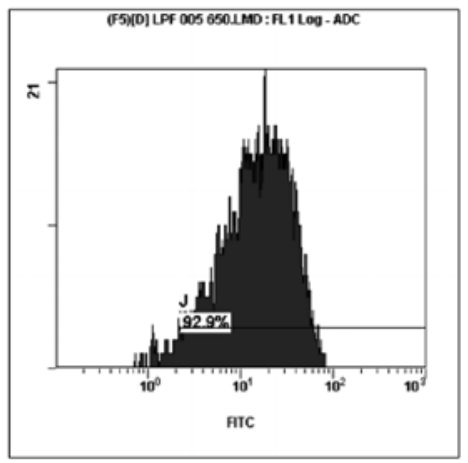

$2 \mu \mathrm{l}: 4 \mu \mathrm{l}$

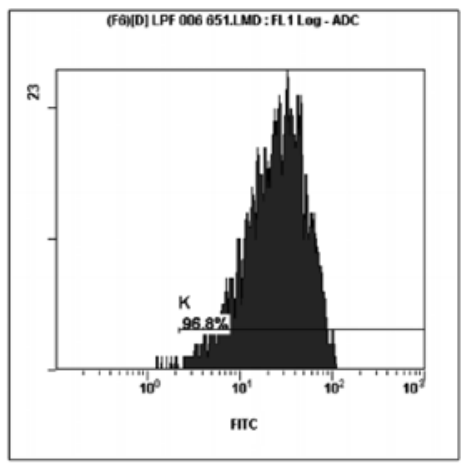

$6 \mu \mathrm{l}: 6 \mu \mathrm{l}$

Figure 2. Transfection efficiency determined by flow cytometry in HCT116 cells. The maximal transfection efficacy could be obtained when the ratio of Lipofectamine 2000 to small interfering RNA (siRNA) was $4 \mu 1: 4 \mu 1$, and the concentration of pancreatic adenocarcinoma upregulated factor (PAUF)-siRNA was $80 \mathrm{pmol} / \mathrm{l}$. The transfection efficiency was $96.9 \% 6 \mathrm{~h}$ after transfecting with PAUF-siRNA of HCT116 cells.

A

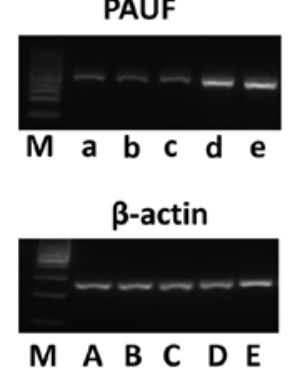

C

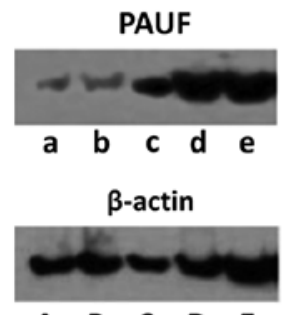

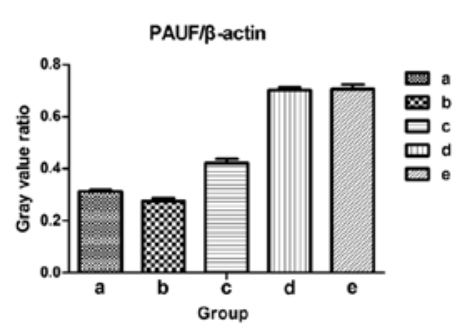

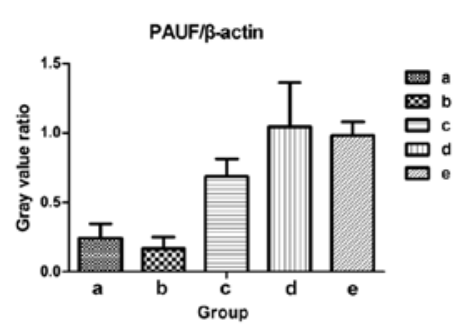

\section{B}
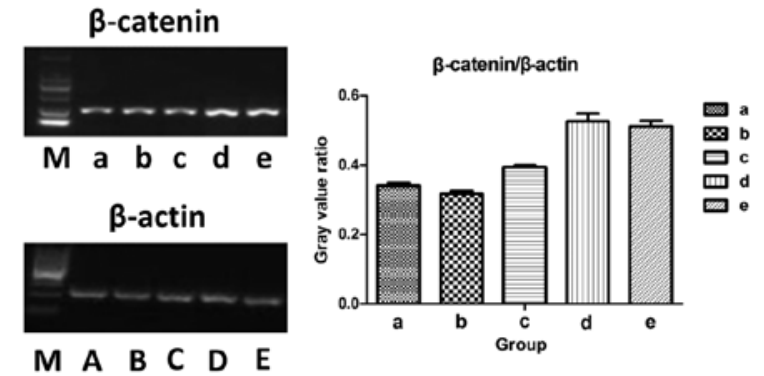

D
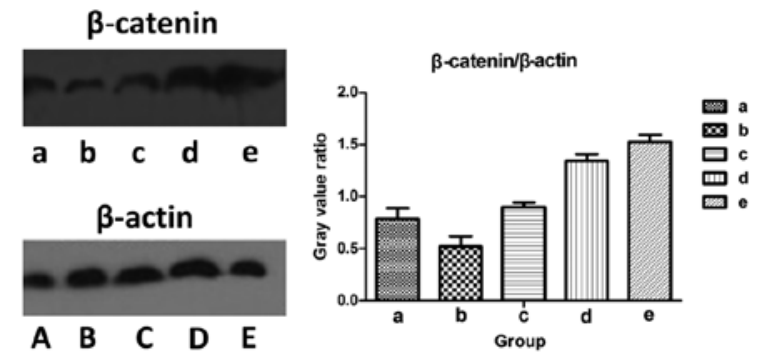

Figure 3. Pancreatic adenocarcinoma upregulated factor (PAUF) and $\beta$-catenin expression level in PAUF-small interfering RNA (siRNA) transfected HCT116 cells. (A and B) PAUF and $\beta$-catenin mRNA expression of PAUF-siRNA transfected HCT116 cells detected by RT-PCR. After $48 \mathrm{~h}$ of PAUF-siRNA transfection, RT-PCR was performed to detect PAUF (A) and $\beta$-catenin (B) mRNA expression. (a) PAUF-siRNA1 group; (b) PAUF-siRNA2 group; (c) PAUF-siRNA3 group; (d) scrambled siRNA group; (e) non-siRNA group. Lanes A,B,C,D,E represent corresponding internal reference. M, marker. Results are given as average value of the gray in 3 target genes and internal controls from 3 independent experiments. (C and D) Representative western blot analysis of PAUF and $\beta$-catenin expression level in PAUF-siRNA transfected HCT116 cells. After $48 \mathrm{~h}$ of PAUF-siRNA transfection of HCT116 cells, protein expression of PAUF (C) and $\beta$-catenin (D) was determined by western blot assay. (a) PAUF-siRNA1 group; (b) PAUF-siRNA2 group; (c) PAUF-siRNA3 group; (d) scrambled siRNA group; (e) non-siRNA group. Lanes A,B,C,D,E represent corresponding internal reference. Results are given as average value of the gray in 3 target genes and internal controls from 3 independent experiments. 


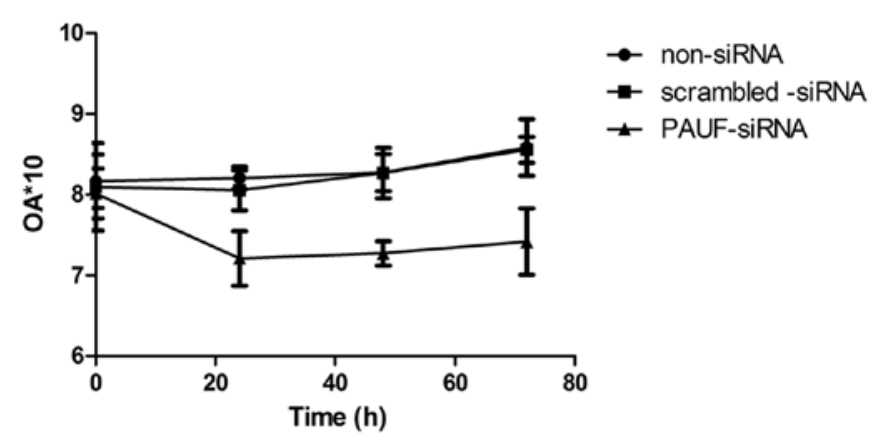

Figure 4. Cell proliferation activity after transfection of pancreatic adenocarcinoma upregulated factor (PAUF)-small interfering RNA (siRNA) assessed by MTT assay. Curves of HCT116 cell growth after transfection for 24, 48 and $72 \mathrm{~h}$ by MTT assay. Results are given as the means \pm SD from 3 independent experiments.

Effect of PAUF-siRNA transfection on the growth of HCT116 cells. In phenotype analysis, we investigated the effect of PAUF on cell growth of HCT116 cells. The cell viability was reduced significantly after treatment with PAUF siRNA at 24, 48 and $72 \mathrm{~h}$ compared with other control groups $(\mathrm{P}<0.05)$ (Fig. 4). The results indicated that RNA interference mediated specific downregulation of PAUF induced strong inhibition of CRC cell growth.

Effect of PAUF-siRNA transfection on the apoptosis and cell cycle of HCT116 cells. We performed experiments to evaluate the apoptosis and cell cycle distribution of HCT116 cells with
PAUF-siRNA by PI staining. The results showed that following $48 \mathrm{~h}$ of transfection, the rate of apoptosis in the PAUF-siRNA group $(36.4 \pm 1.24 \%)$ was significantly higher than that of the scrambled siRNA $(18.3 \pm 1.74 \%)$ and non-siRNA groups $(16.6 \pm 1.84 \%)(\mathrm{P}<0.01)$ (Fig. 5A). On the other hand, the cell cycle analysis in the PAUF-siRNA group showed increased G0/G1 phase cells $(66.59 \pm 4.15 \%, \mathrm{P}<0.05)$ and decreased percentage of $\mathrm{S}$ and $\mathrm{G} 2 / \mathrm{M}(20.97 \pm 2.15 \%, \mathrm{P}<0.05)$ phase cells.

Effect of PAUF-siRNA transfection on the invasion, adhesion and migration of HCT116 cells. Invasion capability was measured in Transwell chambers (CoStar Group Inc.) according to the manufacturer's protocol. The cells that had invaded through the Matrigel-coated filter were fixed in ethanol and stained with crystal violet. The cells were counted under a microscope on 5 random fields at x100 (Fig. 6A). Dye bound to the cells was solubilized with $0.1 \%$ SDS, and absorbance at $560 \mathrm{~nm}$ was measured. The A560 value represents the number of cells that had invaded through the Matrigel-coated filter. The histograms represent the quantification of cells that invaded through Matrigel (Fig. 6C).

Changes in adhesion were evaluated by cell adhesion assay. The A560 value represents the number of cells that adhered to the Matrigel. The adhesion rate $=$ the number of adhered cells/the number of total cells x $100 \%$. Results showed that the adhesion rate of the PAUF-siRNA transfected group was $(49.52 \pm 2.45 \%)$, which was significantly lower than that of the scrambled siRNA $(78.23 \pm 3.86 \%)$ and the non-siRNA group $(89.59 \pm 4.23 \%)(\mathrm{P}<0.05)($ Fig. $6 \mathrm{E})$.

\section{A}
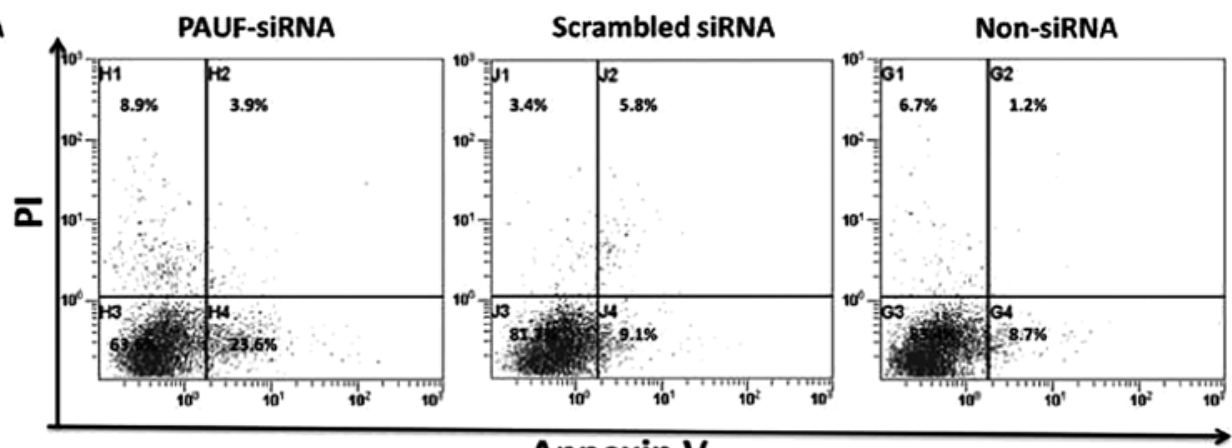

B

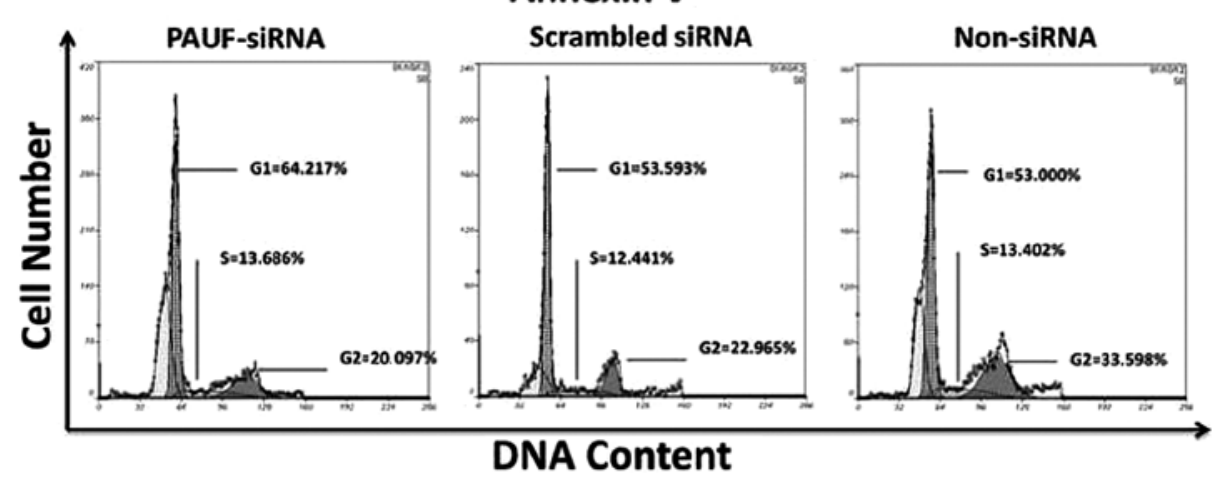

Figure 5. Effect of pancreatic adenocarcinoma upregulated factor (PAUF)-small interfering RNA (siRNA) transfection on the apoptosis and cell cycle of HCT116 cells. (A) Effect of PAUF-siRNA transfection on the apoptosis of HCT116 cells; $48 \mathrm{~h}$ after transfection, cell apoptosis was determined by FACS. Quadrants H2-H4/U2-U4/G2-G4 represent necrotic/late apoptotic cells, viable cells and early apoptotic cells, respectively. (B) Effect of PAUF-siRNA transfection on the cell cycle of HCT116 cells; $48 \mathrm{~h}$ after transfection, cell cycle was determined by FACS. Results are given as the means \pm SD from 3 independent experiments. 
A
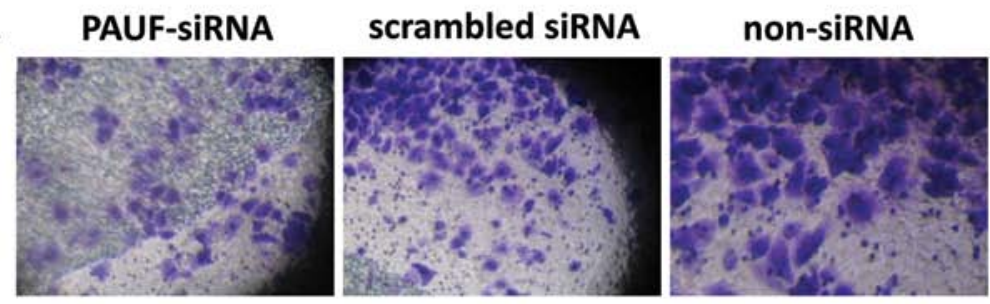

B

PAUF-siRNA

\section{h}

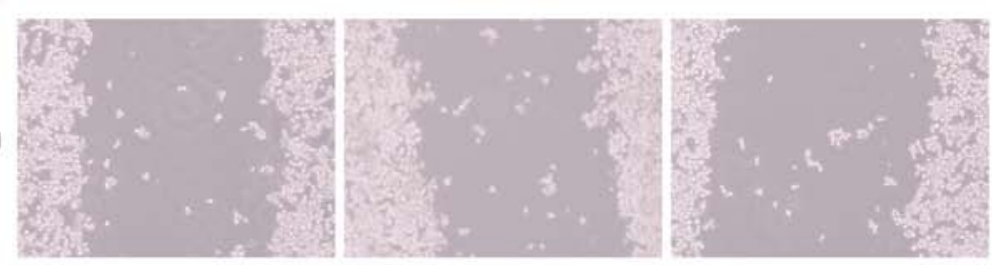

$24 \mathrm{~h}$

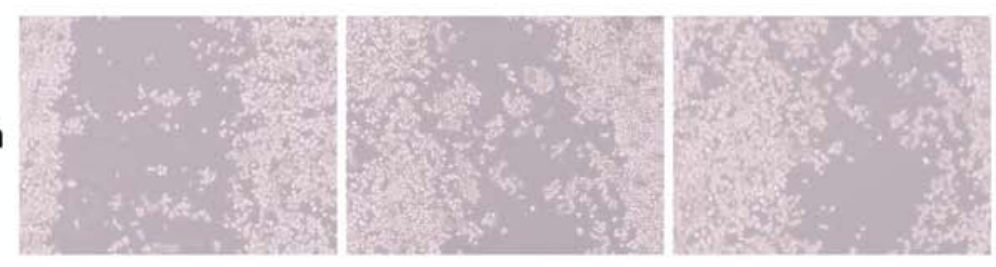

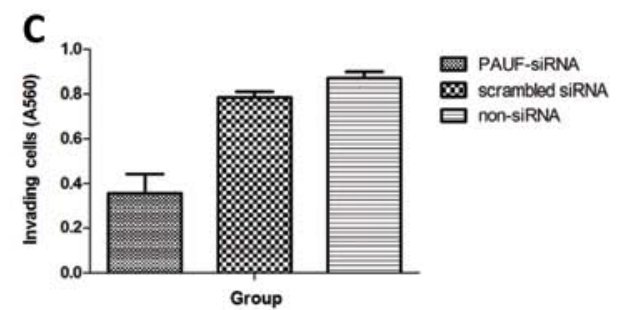

D

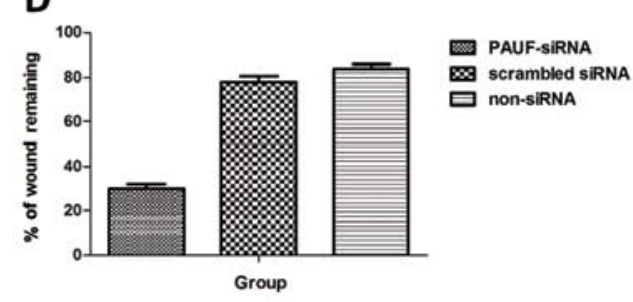

E

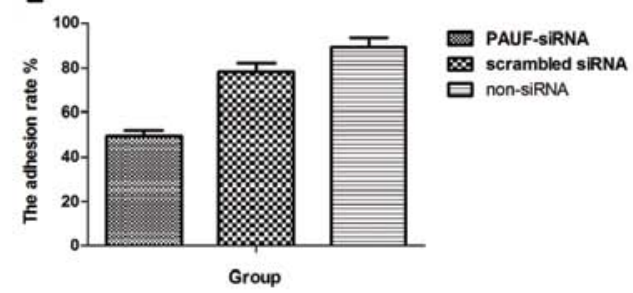

Figure 6. Effect of pancreatic adenocarcinoma upregulated factor (PAUF)-small interfering RNA (siRNA) transfection on the invasion, adhesion and migration of HCT116 cells. The cells were subjected to invasion (A and C), adhesion (E) and migration (B and D) assays $24 \mathrm{~h}$ after transfection, respectively. (C-E) The histograms represent the quantification of cells that invaded through Matrigel, the wound width remaining and the adhesion rate. Data represent 3 independent experiments.

Cell migration assay was performed by the woundhealing method. Images were captured immediately after cell wounding $(0 \mathrm{~h})$ and at $24 \mathrm{~h}$ after cell wounding (Fig. 6B). Wound healing rate $=(0 \mathrm{~h}$ scratch width $-24 \mathrm{~h}$ scratch width) $/ 0 \mathrm{~h}$ scratch width $\mathrm{x} 100 \%$. The results showed that the wound healing rate of the PAUF-siRNA transfected group was $30.54 \pm 3.35 \%$, which was significantly lower than that of the scrambled siRNA $(78.67 \pm 2.81 \%)$ and the non-siRNA group $(84.79 \pm 2.63 \%)(\mathrm{P}<0.01)$ (Fig. 6D).

\section{Discussion}

In the present study, we examined the expression pattern of PAUF transcript and protein in CRC tissues and cell lines, and our findings demonstrated that PAUF is highly expressed in $\mathrm{CRC}$ at the transcript and protein level when compared with NATs. Wee also evaluated the role of PAUF in the biological behavior of CRC through the adjustment of the Wnt $/ \beta$-catenin pathway.

The disorder of several genes, and cell signaling pathways involved in the evolution of CRC, has been extensively investigated and mutations of key genes in the Wnt/ $\beta$-catenin signaling pathway play an important role in the occurrence and development of CRC $(1,14)$. Furthermore, $\beta$-catenin plays a critical role in this signaling pathway $(15,16)$. Previous studies have shown that the regulation of $\beta$-catenin is multifactorial (17), such as CDK8 $(2,17,18)$ of E2F1 (19). Whether other genes play a decisive role in regulating the stability o $\beta$-catenin remains to be examined. In the current study, we focused on gene silencing techniques to detect whether PAUF, a newly discovered oncogene, is involved in the regulation of $\beta$-catenin and whether PAUF participates in the evolution of CRC.

Several studies have demonstrated that the new oncogene PAUF is highly expressed in pancreatic cancer, CRC, ovarian cancer and gastric cancer tissues $(12,13)$, and there is evidence to show that in pancreatic cancer, PAUF can contribute to the oncogenesis of pancreatic cells by upregulating the expression and transcriptional activity of $\beta$-catenin (13). PAUF also plays important roles in cancer progression, including cell proliferation, adhesion, migration and invasion (20-23). In our present study, we detected the expression levels of PAUF in 48 cases of CRC by using real-time RT-PCR. Our data demonstrated that PAUF expression levels were significantly upregulated in cancer tissues compared to NATs, and the expression of PAUF was related to the expression of $\beta$-catenin in both tumor tissues and NATs. These data shows that PAUF may be involved in the evolution of CRC by regulating the Wnt/ $\beta$-catenin pathway.

In order to obtain a deeper understanding of the functional mechanism of PAUF in the initiation and progression of CRC, we employed the RNA interference technique for knockdown of PAUF expression in HCT116 cells. The RNA interference allows inexpensive and rapid analysis of gene function in mammals and represents an effective approach that could be exploited for gene therapy $(24,25)$. In our study, we observed that PAUF inhibitor can markedly inhibit the cell proliferation in HCT116 cells. Flow cytometry analysis found that the cell 
apoptotic rate in the PAUF inhibitor group was significantly higher than in the NC group. The cell cycle data also revealed that the cells of $\mathrm{S}$ and $\mathrm{G} 2 / \mathrm{M}$ phase in the PAUF inhibitor group were markedly lower than in the NC group, while cells of the G0/G1 phase were significantly increased. This suggests that PAUF downregulation may induce G0/G1 cell cycle arrest, more cell apoptosis and the inhibition of cell proliferation in HCT116 cells. After silencing the expression of PAUF, we found that PAUF-siRNA not only inhibited the proliferation of CRC cells, promoted their apoptosis and arrested these cells in the $\mathrm{G} 0 / \mathrm{G} 1$ phase, but also the invasion, adhesion and migration of the tumor cells were inhibited to varying degrees.

Although the precise molecular mechanisms of PAUF in CRC have not been fully clarified, our study, for the first time, illustrated that PAUF could effectively influence the malignant phenotypes of CRC through the Wnt/ $\beta$-catenin pathway. A deeper understanding of its clinical implications and targeted therapeutic interventions in $\mathrm{CRC}$ requires further investigation.

In summary, the current study showed that PAUF is involved in the progression of CRC development by regulating the Wnt/ $\beta$-catenin pathway, and PAUF downregulation with RNA interference can inhibit proliferation, apoptosis, cell cycle progression, invasion, adhesion and migration of cancer cells. These results also suggested that PAUF may serve as an efficient biomarker for diagnosis and is a novel prognostic indicator in CRC. Our study represents a potential new approach to understanding the role of this gene function in cancer and provides a novel strategy for CRC therapy.

\section{Acknowledgements}

This work was supported by Project of Medical Science and Technology Development Foundation of Jiangsu Province of PR. China (H201209), Project of Nature Science Foundation of P.R. China (81201905), Nature Science Research Grants in University of Jiangsu Province of P.R. China (12KJB320009), Shanghai Postdoctoral Scientific Program of P.R. China (13R21415200) and the Science and Technology Research Project of in Science and Technology Bureau of Suzhou city of P.R. China (SYS201220).

\section{References}

1. Jemal A, Bray F, Center MM, Ferlay J, Ward E and Forman D: Global cancer statistics. CA Cancer J Clin 61: 69-90, 2011.

2. He SB, Yuan Y, Wang L, Yu MJ, Zhu YB and Zhu XG: Effects of cyclin-dependent kinase 8 specific siRNA on the proliferation and apoptosis of colon cancer cells. J Exp Clin Cancer Res 30: 109,2011

3. Wan D, He S, Xie B, Xu G, Gu W, Shen C, Hu Y, Wang X, Zhi Q and Wang L: Aberrant expression of miR-199a-3p and its clinical significance in colorectal cancers. Med Oncol 30: 378, 2013.

4. Ferlay J, Shin HR, Bray F, Forman D, Mathers C and Parkin DM: Estimates of worldwide burden of cancer in 2008: GLOBOCAN 2008. Int J Cancer 127: 2893-2917, 2010.

5. Markowitz SD and Bertagnolli MM: Molecular origins of cancer: molecular basis of colorectal cancer. N Engl J Med 361: 2449-2460, 2009.
6. Walther A, Johnstone E, Swanton C, Midgley R, Tomlinson I and Kerr D: Genetic prognostic and predictive markers in colorectal cancer. Nat Rev Cancer 9: 489-499, 2009.

7. Chen HJ, Hsu LS, Shia YT, Lin MW and Lin CM: The $\beta$-catenin/TCF complex as a novel target of resveratrol in the Wnt $/ \beta$-catenin signaling pathway. Biochem Pharmacol 84: 1143-1153, 2012.

8. Firestein R and Hahn WC: Revving the Throttle on an oncogene: CDK8 takes the driver seat. Cancer Res 69: 7899-7901, 2009.

9. Luu HH, Zhang R, Haydon RC, Rayburn E, Kang Q, Si W, Park JK, Wang H, Peng Y, Jiang W and He TC: Wnt $/ \beta$-catenin signaling pathway as a novel cancer drug target. Curr Cancer Drug Targets 4: 653-671, 2004.

10. Dihlmann S and von Knebel Doeberitz M: Wnt/ $\beta$-cateninpathway as a molecular target for future anti-cancer therapeutics. Int J Cancer 113: 515-524, 2005.

11. Kundu JK, Choi KY and Surh YJ: $\beta$-catenin-mediated signaling: a novel molecular target for chemoprevention with antiinflammatory substances. Biochim Biophys Acta 1765: 14-24, 2006.

12. Kim SA, Lee Y, Jung DE, Park KH, Park JY, Gang J, Jeon SB, Park EC, Kim YG, Lee B, Liu Q, Zeng W, Yeramilli S, Lee S, Koh SS and Song SY: Pancreatic adenocarcinoma up-regulated factor (PAUF), a novel up-regulated secretory protein in pancreatic ductal adenocarcinoma. Cancer Sci 100: 828-836, 2009.

13. Cho IR, Koh SS, Min HJ, Kim SJ, Lee Y, Park EH, Ratakorn S, Jhun BH, Oh S, Johnston RN and Chung YH: Pancreatic adenocarcinoma up-regulated factor (PAUF) enhances the expression of $\beta$-catenin, leading to a rapid proliferation of pancreatic cells. Exp Mol Med 43: 82-90, 2011.

14. Bienz $M$ and Clevers H: Linking colorectal cancer to Wnt signaling. Cell 103: 311-320, 2000.

15. Nelson WJ and Nusse R: Convergence of Wnt, $\beta$-catenin, and cadherin pathways. Science 303: 1483-1487, 2004.

16. Coluccia AM, Benati D, Dekhil H, De Filippo A, Lan C and Gambacorti-Passerini C: SKI-606 decreases growth and motility of colorectal cancer cells by preventing pp60(c-Src)-dependent tyrosine phosphorylation of $\beta$-catenin and its nuclear signaling. Cancer Res 66: 2279-2286, 2006.

17. Seo JO, Han SI and Lim SC: Role of CDK8 and $\beta$-catenin in colorectal adenocarcinoma. Oncol Rep 24: 285-291, 2010.

18. Firestein R, Bass AJ, Kim SY, Dunn IF, Silver SJ, Guney I, Freed E, Ligon AH, Vena N, Ogino S, Chheda MG, Tamayo P, Finn S, Shrestha Y, Boehm JS, Jain S, Bojarski E, Mermel C, Barretina J, Chan JA, Baselga J, Tabernero J, Root DE, Fuchs CS, Loda M, Shivdasani RA, Meyerson M and Hahn WC: CDK8 is a colorectal cancer oncogene that regulates $\beta$-catenin activity. Nature 455: 547-551, 2008.

19. Morris EJ, Ji JY, Yang F, Di Stefano L, Herr A, Moon NS, Kwon EJ, Haigis KM, Näär AM and Dyson NJ: E2F1 represses $\beta$-catenin transcription and is antagonized by both pRB and CDK8. Nature 455: 552-556, 2008.

20. Lee Y, Kim SJ, Park HD, Park EH, Huang SM, Jeon SB, Kim JM, Lim DS and Koh SS: PAUF functions in the metastasis of human pancreatic cancer cells and upregulates CXCR4 expression. Oncogene 29: 56-67, 2010.

21. Park HD, Lee Y, Oh YK, Jung JG, Park YW, Myung K, Kim KH, Koh SS and Lim DS: Pancreatic adenocarcinoma upregulated factor promotes metastasis by regulating TLR/CXCR4 activation. Oncogene 30: 201-211, 2011.

22. Lee YS, Kim SJ, Min HJ, Jo JY, Park EH and Koh SS: PAUF promotes adhesiveness of pancreatic cancer cells by modulating focal adhesion kinase. Exp Mol Med 43: 291-297, 2011.

23. Kim YH, Sung HJ, Kim S, Kim EO, Lee JW, Moon JY, Choi K, Jung JE, Lee Y, Koh SS, Rhee SG, Heo K, Kim IH: An RNA aptamer that specifically binds pancreatic adenocarcinoma up-regulated factor inhibits migration and growth of pancreatic cancer cells. Cancer Lett 313: 76-83, 2011.

24. Merritt WM, Bar-Eli M and Sood AK: The dicey role of dicer: implications for RNAi therapy. Cancer Res 70: 2571-2574, 2010.

25. Brummelkamp TR, Bemards R and Agami R: Stable suppression of tumorigenicity by virus-mediated RNA interference. Cancer Cell 2: 243-247, 2002. 